
$\$$ Research Square
Preprints are preliminary reports that have not undergone peer review.
They should not be considered conclusive, used to inform clinical practice,
or referenced by the media as validated information.

\title{
The Course of Biotinidase Activities After Neonatal Period in The Screened Newborns and Consequences of The Concordance With Their Genotypes.
}

Murat Karaoglan ( $\square$ muratkaraoglan@gantep.edu.tr)

Gaziantep Universitesi Tip Fakultesi https://orcid.org/0000-0002-2861-3568

Gulper Nacarkahya

Gaziantep Universitesi Tip Fakultesi

Emel hatun Aytac

Gaziantep Universitesi Tip Fakultesi

Mehmet Keskin

Gaziantep Universitesi Tip Fakultesi

\section{Research Article}

Keywords: biotinidase deficiency, genotype-biochemical phenotype discordance, biotinidase activity

Posted Date: October 27th, 2021

DOI: https://doi.org/10.21203/rs.3.rs-1004063/v1

License: (9) This work is licensed under a Creative Commons Attribution 4.0 International License. Read Full License 


\section{Abstract}

Background/aim: Biotinidase deficiency (BTD) is characterized by broad genotypic variants and unsteady biotinidase activity. Increasing enzyme activity and maturation throughout childhood. This study aims to reveal the course of biotinidase activities in a long-term follow-up period and concordance with their genotypes .

Participants/Methods: A total of 1,773 biotinidase enzyme (BT) activity measurements were performed in 711 newborns with variants in the BTD gene over a 4-year follow-up period. Biochemical phenotyping was classified into four groups based on the highest measured enzyme activity level during the follow-up: Profound( $\leq 10 \%)$, Partial(10.1-30\%), Heterozygous(30.1-66.5\%), and Normal( $>66.6 \%)$.

Results: The number of participants with BTD in the biochemical phenotype groups assigned based on the first measurement was 59,217 , 314 , and 121 in the profound, partial, heterozygous, and normal groups respectively. Based on the highest measurement value during follow-up, the number and net changes of participants in groups were 22(-37), 95(-122), 333(+19), and 261(+140), respectively. The overall concordance between genotypes and biotinidase activities based on the highest measurement was $50.7 \%$. A moderate correlation was found between the highest enzyme value and age $(r=-0.573, p=0.002)$ in heterozygous plus normal biochemical phenotype groups in first months.

Conclusion:This study shows that the biotinidase activities increase at a later age after neonatal period during long-term follow-up, and there is low concordance between the biochemical phenotype and their genotype. These findings indicate the important role of the monitoring the course of biotinidase enzyme activities for a longer period of time to determine the treatment decision.

\section{What Is Known}

- Biotinidase enzyme activity is low in newborns compared to later ages.

- Biotinidase activity increases with age, which changes biotin treatment approaches.

\section{What is new}

- This paper reports long-term results of biotinidase activity after the neonatal period.

- This paper reports genotype concordance of varying biochemical phenotypes.

\section{Introduction}

Biotin is a micronutrient that plays a role in fat, carbohydrate, and protein metabolism. It acts as a cofactor of four important carboxylase enzymes (1). Biotinidase is an enzyme that recycles biotin by releasing it from biotinylated proteins such as holocarboxylase. Children with severe biotinidase deficiency (BTD) can present with neurodevelopmental delay, seizure, visual loss, sensorineural hearing loss, rash, and even immune disorders at any age from newborn to adulthood if untreated $(1,2)$. Untreated cases with severe BTD may present with metabolic acidosis, lactic acidosis, and hyperammonemia. After neonatal screening implementations, poor clinical consequences became preventable with early diagnosis. Definitive diagnosis for BTD is based on measuring enzyme activity (3). There are four biochemical phenotypes defined using a classification based on residual enzyme activity: profound $(\leq 10 \%)$, partial (10.1-30\%), heterozygous (30.1$66.5 \%)$, and normal (>66.6\%) (4).

BTD is one of the most common inborn metabolic disorders inherited by an autosomal recessive pattern (1). The incidence is 1:40 000-1: 60 000/live birth, although it may vary between countries by ethnicity $(5,6,7)$. In Turkey, the disease frequency is as high as 1:7116 (8). Similarly, the incidence is higher in countries where consanguineous marriage is high, such as Saudi Arabia and the United Arab Emirates $(7,9)$.

Genotype and biochemical phenotype concordance may not always be as expected in BTD, and it may cause challenges in diagnosis, follow-up, and treatment. To date, over 200 pathogenic variants have been identified for the BTD gene responsible for BTD (10). Globally, the most common variant is p.D444H, but the incidence rate varies from country to country $(11,12,13)$. The various combinations of severe and mild variants in the alleles cause the phenotypic variation, and the biochemical properties of biotinidase may lead to an unsteady biochemical phenotype. Biotinidase activity does not act along a continuous spectrum (14). Therefore, using specified cut-off values to identify the phenotypes may not always reflect the expected genotype. Biotinidase activity shows biphasic kinetics, which can lead to clinical heterogeneity (15). In addition, enzyme maturity develops with age (16). The screening tests for BTD are usually performed within 3-5 days when the enzyme activity value is the lowest. Therefore, phenotypic groups identified in the early neonatal period can change. These factors pose challenges in evaluating neonatal screening results, and newborns are over-diagnosed with BTD. Appropriate 
treatment may be difficult for each patient, and it can also lead to increased concerns about cost-effectiveness (17). Furthermore, some methodological issues in biotinidase enzyme activity measurement can confuse the relationship between phenotype and genotype $(18,19)$.

The most commonly used method for biotinidase activity measurement is colorimetric assay. It is well known that the following affect the measurement $(3,18)$ : preanalytical conditions such as neonatal jaundice, prematurity, temperature, storage and transport conditions, or issues with the analytical method such as quantification, calibration, reference intervals, or even post-analytical conditions such as test interpretation and reporting errors. Therefore, previous some guidelines were prepared for the elimination and standardization of analytical issues (14).

Considering all these, making a decision based on a single biotinidase measurement in the neonatal period alone will lead to confusion in determining the biochemical phenotype, clinical follow-up and appropriate treatment. Currently, there have not been enough studies reporting long-term consequences by performing multiple biotinidase activity tests. This study aimed to reveal the long-term results of the compatibility between genotype and biochemical phenotype by performing sequential tests over a 4-year follow-up period.

\section{Participants And Methods}

This was a single-center, observational, cross-sectional study. Approval was obtained from the Clinical Research Ethics Committee. Written consent was obtained from all parents. Following the national screening protocol, the first blood sample was collected with filtered papers 3-5 days after birth. Patients with a positive result for biotinidase deficiency applied to our centerfor confirmation within the first month after birth. The study population consisted of these children, referred for diagnosis confirmation and follow-up. Confirmation tests were quantitatively studied using the colorimetric method. More than one enzyme activity measurement was performed if the enzyme activity was lower than $30 \%$ of the normal enzyme activity or it was detected to be between cut-off borderlines to determine biochemical phenotypes (borderline; cut-off point \pm 0.1 ). The test was repeated when there was a presence of discordance between expected phenotypes versus genotype. Molecular analysis was performed for BTD gene variants on all participants.

\section{Participants}

Participants $(n=711)$ consisted of non-relative newborns referred to the Neonatal Biotinidase Screening Program with positive results between March 2016 and December 2019. The numbers of participants admitted over the years of the study were as follows: 2016 ( $n=88$ ), $2017(n=140), 2018(n=238)$, and $2019(n=245)$. The vast majority of the first confirmatory tests were carried out within the first month after birth. There was an average of 3 months ( \pm 15 days) between multiple enzyme activity measurements. The ages of the participants were determined as days. A total of 1,773 enzyme activity measurements were performed on all participants. The number of performed tests for participants was as follows: 2 times for 625,3 times for 285 , and 4 times for 152 participants. Only one test (in the neonatal period) was performed for 86 patients.

Except for hearing loss in a newborn with profound BTD, there was no patient with clinical signs of BTD during the follow-up. Patients whose enzyme activity was not measured in the neonatal period or who were diagnosed with BTD at an older age were excluded from the study.

\section{Determination of biochemical phenotype groups}

The biochemical phenotypes were classified based on the highest biotinidase enzyme activity value over different time points after four sequential tests. The highest test value was assigned as the highest measurement from the four tests performed at different time points during the follow-up. Biochemical phenotyping is divided into four groups based on biotinidase enzyme activity (19): profound ( $\leq 10 \%$ of the healthy children), partial (10.1-30\%), heterozygous (30.1-66.5\%), and normal $(>66.6 \%)$.

\section{Clinical classification}

In terms of clinical classification, the profound and partial groups were named the Treated group, while those not given biotin were defined as the untreated group, since the heterozygous and normal groups displayed sufficient enzyme activity levels. Oral biotin treatments of 10 $\mathrm{mg} /$ day (in profound) and $5 \mathrm{mg} /$ day (in partial) were given according to enzyme activity. In cases with genotype-phenotype discrepancy, the treatment decision was made based on enzyme activity level, including actual clinical course, considering the poor genotype-phenotype correlation in BTD. 
All enzyme activity measurements were performed on serum samples. The colorimetric method was used to measure quantitative enzyme activity throughout the period of the study. After centrifugation, serum samples were stored at $-80^{\circ} \mathrm{C}$ until analysis. The collection and transfer of the samples to the laboratory where the analysis was carried out were ensured by complying with the cold chain conditions that preserve the stability of biotinidase. Prior and throughout the analysis, the temperature conditions that preserve the stability of biotinidase were maintained for patients' sera. The colorimetric method was used to measure quantitative enzyme activity throughout the period of the study. Biotinyl-p-aminobenzoic acid was used as the substrate. After incubation, $100 \mu$ of trichloroacetic acid was added to $10 \mu \mathrm{l}$ of supernatant, and $100 \mu \mathrm{l}$ of new supernatant obtained after centrifugation was added to the wells. Then, the obtained samples were incubated with reagent 1-2-3, respectively. The adsorbents obtained were read using the spectrophotometer device (BioTek Instruments, Winooski, VT, USA) at a wavelength of 570 nanometers. Just prior to analysis of each set of patient sample sera, the positive (low) and normal (control) serum pools obtained according to literature guidelines and manufacturer's instructions were used to perform quality control (14). Strict temperature control was also kept for positive and control serum pools. For intra-assay precision, controls ( $\mathrm{n}=22$ ) generally showed that the CV was less than $10 \%$. For inter-assay precision, controls within normal limits ( $\mathrm{n}=10$ ) generally showed that the CV was less than $10 \%$. The normal reference range was $3.5-13.8 \mathrm{nmol} / \mathrm{min} / \mathrm{mL}$ The biochemical phenotype groups were assigned by the mean enzyme activity of healthy children $(7.5 \mathrm{nmol} / \mathrm{min} / \mathrm{mL})$. Enzyme activity of $>66.5 \%$ above was considered as $100 \%$.

Molecular analysis

DNA was isolated by using Sanger sequence method (AB $3130 \mathrm{XL}$ ) after amplification with PCR (Maxwell RSC Whole Blood DNA kitPromega, USA). The intronic regions and known mutation regions (1, 2, 3 and 4. Exons) for the BTD gene were scanned (forward and reverse chain). Ensemblgen scanner (genomic reference NM000060, transcript ID ENST00000643237.3) was used as the reference sequence for the $B T D$ gene.

The published database or pub med was used to name the mutations called severe or mild. Clinical significance and variant pathogenicity for the BTD gene were evaluated using Varsome (https://varsome.com), Clinvar, Mutationtester (www.mutation taster.org), pubmed and Ensembl (https://www.ensembl.org).

\section{Determination of the Concordance between Genotype and Biochemical Phenotypes}

The genotypes were classified into 7 subgroups according to the severity of the variants in both alleles (19): (a) Severe(S)-Severe (homozygote, HMZ), (b) Severe-Severe (compound heterozygote, C/H), (c) Severe-Mild (M) (C/H), (d) Severe-No (heterozygote, HTZ), (e) Mild-Mild (HMZ), (f) Mild-Mild (C/H), and (g) Mild-No(HTZ). The expected enzyme activity groups for each genotype were determined as follows: Severe-Severe (HMZ and C/H); Profound, Severe-Mild (C/H); Partial, Severe-No (HTZ); Heterozygous, Mild-Mild (HMZ and C/H); Heterozygous, Mild-No; and Normal. Expected enzyme activity groups according to genotype and observed groups were compared and then the compatibility was calculated between genotype and biochemical phenotype.

\section{Statistics}

The statistical analyses were performed by using Statistical Package for Social Sciences version 22.0 (IBM Inc., Chicago, IL, USA). For continuous variables, normality of distribution was confirmed using the Shapiro-Wilk test. Statistical analyzes related to biotinidase enzyme activity were performed on the values of participants who had four consecutive enzyme activity measurements One-way repeated ANOVA test was used to detect the significant difference between age and mean enzyme activity measurements in phenotype groups. ChiSquare test was used to determine the significance between expected and observed enzyme activity groups. Spearman rho correlation test was used to determine the following correlations: a) Correlation between the enzyme activation groups in the first and subsequent tests. b) Correlation between age and enzyme activities.

\section{Results}

\section{Biochemical phenotype groups and measurements of biotinidase enzyme activity}

According to biochemical phenotyping based on the highest biotinidase activity values over different time points, the distribution of all cases ( $n=711)$ was as follows: 22 (3\%) profound, 95 (13.4\%) partial, $333(46.8 \%)$ heterozygous, and 261 (36.7\%) of the normal groups. Of them, 117 (16.4\%) were in the treated group requiring biotin treatment, while the remaining 594 (83.6\%) were in the untreated group. Of the participants, 325 (45.8\%) were female. Table 1 shows the mean ages of testing performed at different time points, the mean enzyme activity determined for each test time, and the distribution of total cases undergoing four tests ( $n=152)$ in each group. There was a difference between the phenotypic groups for the age of the first test $(p=0.015)$. The mean biotinidase enzyme activities were significant between biochemical phenotype groups based on highest test values over different periods after four sequential 
tests $(8.08 \pm 4.30,20.33 \pm 6.44,39.33 \pm 29.30$, and $73.28 \pm 27.56$ in the profound, partial, heterozygous, and normal groups, respectively) $(p=0.012)$ (Figure 1). In the profound and partial groups, there was no difference in the mean enzyme activity levels between four tests performed over different time points, there were no differences $(p=0.525 ; p=0.483)$, but the differences were significant in the heterozygous and normal groups ( $p=0.016 ; p<0.001$, respectively) (Table 1). A significant difference was also found between four consecutive enzyme activity levels in the untreated group (heterozygous plus normal) $(p<0.001)$. When analyzed, it was found that this significance in the heterozygous and normal groups was due to the differences between the first test and the other tests (second,third, and fourth tests). In untreated group (heterozygous and/or normal), the mean enzyme activity in the first test during the neonatal period was lower than in those other consecutive tests over different time points $(p<0.001)$.

\section{Changes in the number of participants in the biochemical phenotype groups during follow-up}

The number of cases with BTD in the biochemical phenotype groups assigned based on the first measurement was 59, 217, 314, and 121 in the profound, partial, heterozygous, and normal groups, respectively. When the cases were classified based on the highest measurement value over different time points, the number of cases were 22 (change: $-37 ;-62.7 \%), 95$ (change:-122; $-56.2 \%$ ), 333 (change: $+19 ;+6 \%$ ), and 261 (change: $+140 ;+115 \%$ ), respectively (Figure 2). Figure 2 shows that the number of cases changing and remaining the same in the groups based on the first test and the highest enzyme activity values.

\section{Distribution of alleles in the biochemical phenotype groups}

Among the total alleles ( $n=811$ alleles) the most common was p.D444H, (c.1330G >C) $(n=385,47.7 \%)$. The next two alleles with a high frequency were p.R157H, (c.470G>A) $(n=149,18.3 \%)$ and p p.C33Ffs (c.198_104delGCGGCTGinsTCC $(n=73,9 \%)$. The distribution of alleles detected depending on biochemical phenotypes is given in Table 2. There were 11 cases with the p.D444H, (c.1330G > C) HMZ genotype presented with profound $(n=3)$ and partial $(n=8)$ BTD. Of the p.D444H (c. $1330 \mathrm{G}>$ C) variants, $337(87.5 \%)$ were distributed into heterozygous or normal phenotype groups. Rare alleles including novel variants were called "Other alleles". The rare alleles were as follows: p.C186Y (c.557G>A), p.C143F (c.482G>T), p.C418S (C.1253 G>C), p. p.F128S (C.383 T>C), p.G45R (c.133G>A), p.M86R (c.257T>G), p.L215F (c.643 C>T), p.M86R (c.257T>G), p.N214S (c.641 A>G), p.N402S (c.1205A>G), p.P497S (c.1489C>T), p.R148H (c.443G>A), p.T351 KFs (c.1052delC), p.V457M (c.1369G>A), p.Q511E (c.1531C>G), p.W140Ter (c.419G>A), p.Y454C (c.1361A>C), p.Y93C (c.278A>G). Nine variants were accepted as "novel" since they could not be detected in the specified databases. The novel variants were as follows: p.A101T (C.301 G>A), p.D260Y (c.778 G>T), E64G (c.191A>G), p.G480E(c.1439G>A), p.Q257H, p.G537W(C.1609_1611 delinsTGA), p.G343V(c.1028G>T), p.H518R (c.1553 A>G), p.V199delCGT (c.594_596DEL CGT).

No mutation was detected in 55 cases ( $n=55,7.7 \%)$. Of all cases, $306(47 \%)$ were $\mathrm{HTZ}, 193(29 \%)$ were $\mathrm{HMZ}$, and $157(24 \%)$ were $\mathrm{C} / \mathrm{H}$. The distribution of zygosity according to the phenotype groups is shown in Table 2.

\section{Distribution of genotype groups}

The most common allele pairs were determined as follows: p.D44H (c.1330G > C)-p.D444H (c.1330G > C) $(n=141 / 19.8 \%), p . D 444 H$ (c.1330G > C)-No mutation ( $n=112 / 15.7 \%)$, p.R157H(c.470G>A)-No mutation ( $n=65 / 9.1 \%)$, p.R157H (c.470G>A)-p.D444H(c.1330G >C) $(n=53 / 7.4 \%)$. The frequency and distribution of other allele pairs to genotype groups are given in Figure 3 . The distribution of genotype groups classified according to severity was determined as follows: S-No; 181 (25\%), M-M;163(23\%), M-No; 125(18\%), S-M;124(17\%), SS;63(9\%). Distribution percentages of genotype groups according to phenotypes are given in Figure 3.

\section{Genotype-biochemical phenotype concordance}

When genotype and biochemical phenotypes were compared, the concordance was 50.7\% (Table 3). While the concordance rate was found to be lower in the severe genotypes, it was higher in mild mutations. However, variable frequencies were determined according to the specific allele pair in the groups When the heterozygous group was added to the normal group, concordance rates were as follows: $95 \%$, 91\%, 96.8\%, and $96.3 \%$ for S-no, M-M, M-no, and no mutation genotype groups. Then, global concordance rate was $72.2 \%$ (Table 3).

\section{Correlations related to mean enzyme activity}

There was a moderate correlation between both in the partial group $(r=0.605 ; p=0.035)$, while weak correlation was found in the profound group ( $r=363 ; p=0.001$ ). Except for the partial group, no significant correlation was found between the first test and the other tests over different time points in the other groups.

There was a moderate correlation between biotinidase enzyme activity (\%) and age (days) in heterozygous and normal biochemical phenotype groups in first months ( $r=0.573$ ) (Figure 4). However, no correlations between age and biotinidase enzyme activity were found in 
the profound and partial groups $(r=0.112, r=0.089$, respectively).

\section{Discussion}

This study reveals long-term follow-up consequences for patients diagnosed with BTD. Most of the reports related to BTD are crosssectional studies, and they involve the neonatal or early infant period $(5,8,20)$. Most previous evaluations were performed with single measurement results, while the present study reports the long-term consequences of genotype-phenotype association with the change in consecutive biotinidase enzyme activity results.

In most previous studies, a higher frequency of profound and partial BTD forms was reported in the literature $(5,20,21)$. The frequency of profound BTD determined based on the first test results of this study was found to be similar to (8.2\%) these previous reports. However, in the biochemical phenotyping performed on the highest enzyme activity values obtained during the 4-year follow-up, the percentage of profound BTD decreased to $3 \%$. Fifty-five patients were classified as profound according to the first enzyme activity values performed in the neonatal period. Of these, 16 were assigned the partial, 13 were heterozygous, and 7 were assigned the Normal biochemical group during long-term follow-up. Similarly, of the 217 patients considered in the partial group with the first test, 91 and 49 were placed in heterozygous and normal groups, respectively, during the follow-up. Similar changes were observed in the heterozygous group. The vast majority of these changes occurred within the first three months of life. It was determined that the difference between the first test and the other tests was due to an increase in enzyme activity values during follow-up. The mean enzyme activity in the neonatal period was found to be lower than other tests performed later. Correlation tests performed in untreated groups (heterozygous plus normal) show a positive correlation between age and enzyme activity in the first three months. However, there was no correlation of age with biotinidase activity in the profound and partial groups since enzyme activity does not increase with age.

Biotinidase enzyme activity level is reported to be the lowest in the first days of life, but increases within the following days (5). Therefore, low enzyme activity levels can be predicted in early neonatal confirmation tests with screening performed in the first postnatal period. However, the course of low activity levels later in life has not been adequately studied. Our study results indicate that biotinidase activity results increase with age in the first months of life in infants who had normal enzyme activity. This gradual increase was not seen in patients assigned to the profound and partial groups based on the highest enzyme activity values over different time points. In the untreated group, this pattern seems to reflect the age-related physiological changes in the activity of the biotinidase (16). Screening time for BTD may coincide with the neonatal period when the biotinidase activity level is low. This situation may lead to an overdiagnosis of BTD if satisfied with a single confirmation test for enzyme level.

The variability in biotinidase activity is influenced by the factors arising from various clinical conditions as well as the natural course. These include premature, environmental temperature, transfer conditions of the samples, hyperbilirubinemia, and perinatal asphyxia (14, 22). The necessity of evaluating the effects of possible perinatal factors in the first test with the subsequent confirmatory tests coincides with the study objectives. These findings reveal that the single measurement in the neonatal period is not satisfactory current enzyme activity level, and long-term follow-up with sequential tests to determine biochemical phenotypes in BTD is needed.

The most common variants found were p.D444H (c.1330G > C), p.R157H (c.470G>A), and p.C33Ffs (c.198_104delGCGGCTGinsTCC) (10). Although p.D444H (c.1330G > C) was a mild variant, it was found to be associated with profound group in $3 \mathrm{HMZ}$ cases (p.D444H(c.1330G $>$ C)-p.D444H(c.1330G > C), partial group in 8 cases with HMZ p.D444H(c.1330G > C)-p.D444H(c.1330G > C), and partial group in 3 HTZ cases (p.D444H(c.1330G > C) -No). Contrary to expectations, the p.D444H (c.1330G > C) variant has been reported in previous studies as well, with an association of more severe biochemical phenotypes $(20,23)$. This may be due to the additional contribution of epigenetic factors or double mutations consisting of undetectable severe variant combinations (24). Given that higher rate of consanguineous marriages are common in our region, complex mutations appear to be more frequent $(19,25)$. p.R157H (c.470G>A) was the most common severe variant. However, contrary to the expected phenotype for this genotype, it was found to be a heterozygous biochemical phenotype in two cases with HMZ (R157H (c.470G>A)-R157H(c.470G>A) ), normal biochemical phenotype in one case with HMZ, and normal enzyme activity group in 32 heterozygous genotype (R157H(c.470G>A) -No). It was found that the p.C33Ffs (c.198_104delGCGGCTGinsTCC) variant was seen more frequently in our study, unlike other reports $(20,21)$. Contrary to expectations, normal group was detected in 12 p.C33Ffs (c.198_104delGCGGCTGinsTCC) heterozygous genotype (p.C33Ffs (c.198_104delGCGGCTGinsTCC)-No) cases. Unlike the expected phenotype, milder enzyme activities were observed in severe variant alleles such as p.Q456H(c.1368A>C) and p.T532M(c.1595C>T).

Genotype-phenotype discordance may result from characteristics of biotinidase and circumstances involving enzyme measurements (3, 14). The increase in enzyme maturation and activity appears with age. This physiological feature can alter the biochemical phenotypes. In the present study, phenotyping was performed based on the highest activity value during the long-term period, allowing for changes in 
enzyme activity to be monitored. On the other hand, individual differences in $\mathrm{Km}$ kinetics of biotinidase or preanalytical conditions, such as neonatal jaundice, prematurity, temperature, storage and transport conditions, or problems with the analytical method, such as quantification and calibration issues,can also affect enzyme activity measurements (14). One of the important challenges in determining the biochemical phenotype is that the biotinidase stability is very sensitive to ambient temperature. Therefore, insufficient temperature conditions during the preanalytical process lead to a decrease in enzyme activity (14). A previous study reported that the stability of biotinidase was maintained for 2 hours at room temperature, one day at $4{ }^{\circ} \mathrm{C}$, and four months between $-20{ }^{\circ} \mathrm{C}$ and $-80{ }^{\circ} \mathrm{C}(26)$. If temperature control was not strictly maintained, lower results would be obtained inadvertently instead of expected higher enzyme activity values for milder genotypes, which will lead to genotype-phenotype mismatch. The data obtained from our study were performed under rigorous preanalytical (cold chain-temperature controlled) conditions that preserve the stability of biotinidase enzyme activity for both patient samples and positive/control sera. The main reason for the inconsistency of our study results with previous studies is not the limitations of biochemical or molecular analysis methods, but the changes seen in biotinidase activity with age in the long-term follow-up. The present study results were based on the classification established according to the highest value at different time points, contrary to most previous studies, which were content with single test results in the neonatal period. In our study, 86 patients had only one test performed in the neonatal period. In contrast to falsely lower results due to possible insufficient temperature conditions, higher enzyme activities were detected in the long-term follow-up, even in the more severe genotypes in our study. The results of our study generally reveal that there is an increasing pattern in enzyme activity with age in long-term follow-up, which naturally leads to a shift from more severe to milder biochemical phenotypes. Therefore, we hope that our study results will be a source for further studies to understand the inconsistencies in the genotype-phenotype relationship (molecular basis and environmental influence).

Another reason for genotype-phenotype mismatch in long-term follow-up is that the biotinidase activity of healthy newborns is as low as $50-70 \%$ of adults (14). Ideally, each laboratory should establish its own normal reference ranges for neonates. Otherwise, a discrepancy may be seen in the biochemical phenotypes performed between the neonatal period and later ages. The long-term results of our study provide an important contribution in this respect. The values equal to or close to the cut-off values determined for biochemical phenotypes are also one of the reasons that lead to challenges in biochemical classification. Limit values determined especially for profound-partial and partial-heterozygous groups may cause difficulties to make a decision to start treatment clinically. In our study, we found results equal to or close $( \pm 10 \%)$ to the cut-off values in 23 patients.

Ten patients with p.C33Ffs*36 (c.98_104d7i3) homozygote were also found to have a heterozygous phenotype in 3 of them, contrary to the expected biochemical phenotype. Moreover, the highest values in 6 patients with profound phenotype were found to be close to the cut-off values in long-term follow-up. These findings contradict the literature data for the well-known pathogenic variant p.C33Ffs*36 (c.98_104d7i3) (stop codon in the data beginning " of BTD, resulting in "early" truncated protein) (6). One of the reasons for inconsistency is that the biochemical classification was established based on the highest value in long-term follow-up. The biochemical phenotype expected for the genotype (p.C33Ffs*36 (c.98_104d7i3 homozygote)) was determined change with age and there is a need for reassessment on possible causes of this mismatch. On the other hand, it should be noted that although there is a well-known pathogen variant, there is no evidence of functional analysis in databases. The presence of another undetected variant may also be another reason for this incompatibility.

In the present study, contrary to the expected heterozygous biochemical phenotype for p.D444H (c.1330G> C) homozygous, it was determined as a profound phenotype in three patients. When the biochemical enzyme activities of the patients were re-evaluated, it was noticed that three patients had a single enzyme activity measurement taken in the neonatal period, and the biochemical classification was made according to these values. Moreover, two had close to the cut-off values. We suggest that the discrepancy between biochemical phenotyping and this genotype is due to single measurement and/or close to the cutoff values. On the other hand, when p.D444H (c.1330G > C) homozygous cases co-inherited with the double cis p.A171T (c.511G> A) variant, they present as biochemically profound as opposed to the expected mild phenotype (24).

Contrary to the expected profound biochemical phenotype of 23 children with p.R157H homozygote, which is known to be a pathogenic variant, 17 were partial, two heterozygous, and one normal biochemical phenotype. There is a marked inconsistency with literature data (27). In our study, it should be considered again that the biochemical phenotyping was performed according to the highest enzyme activity result obtained from many tests performed at different time intervals in long-term follow-up. As a matter of fact, if the biochemical phenotyping was performed according to the first test results in our study, 9 of 23 patients would be classified as profound (40\%). We think that one of the important reasons for the inconsistency with the literature data is this difference.

In the first tests, 7 and 49 patients were consistent with profound and partial phenotypes, respectively, while they were classified as normal phenotypes according to the highest value obtained from the tests performed at different time points (Figure 2). Inconsistent with the increase in enzyme activity with age, a shift from more severe to milder biochemical phenotypes was observed, not vice versa. In the case

Page $7 / 17$ 
of a mismatch due to a problem with biochemical analyses, the opposite could be expected. These results are derived from 1773 total test results in a large number of patients $(n=711)$. We suggest that the reason for this shift from more severe phenotypes in the neonatal period to the normal group at later ages may be due to the fact that the enzyme activity in the neonatal period. These discrepancies can be further reduced when corrected for newborn-specific references.

Contrary to expectations for p.Q456H homozygous cases, which is a severe variant, the biochemically heterozygous (>30\%) phenotype has never been reported in the literature. However, in our study, one of these cases had $33 \%$ enzyme activity when he was 15 months old. We also suggest that the difference with the literature is due to the conditions mentioned above.

Dietary intake of adequate biotin may also prevent symptoms from appearing (28). It is suggested that these cases may be symptomatic, such as acute hearing loss after metabolic stresses are exposed at later ages. In the present study, genotype-biochemical phenotype compatibility was $50.7 \%$, which appears to be lower than the previously reported data $(19,21)$. However, when the heterozygous group was added to the normal group (untreated group), concordance rates were as follows: 95\%, 91\%, 96.8\%, and 96.3\% for the S-no, M-M, M-no, and no mutation genotype groups. Thus, the global concordance rate was $72.2 \%$. The concordance was particularly low for the profound and partial groups ( $25 \%$ and $29.6 \%$, respectively).

To date, over 200 pathogenic variants have been identified for the BTD gene (10). However, compatibility with the predicted phenotype for each variant is not always clear enough (29). Cases that are asymptomatic despite having pathologically defined variants, or vice versa, may be seen (30). Promising explanations to clarify our understanding of this mismatch come from studies investigating the relationship between single nucleotide polymorphisms (SNPs) and phenotypes. The effect of SNP is gaining more interest to explain the genotypephenotype relationship (31). SNPs are the most common cause of variants in the genome, and can be neutral or functional. Furthermore, SNPs can affect gene structure and functions by creating nucleotide changes on genes (32). A large number of novel polymorphic variants for the BTD gene are reported every day in various countries. Possible rich combinations of pathogenic variants may lead to diversification of clinical phenotypes, in particular, in countries such as Turkey, Saudi Arabia, and Jordan, where there are high rates of consanguineous marriage $(13,21,33)$. These polymorphic variant combinations also make it difficult to predict the expected phenotype. Apart from that, the expected profound phenotype for the p.R157H (c.470G>A) homozygous variant was previously identified as pathogenic, while of them, 17, 2 and1 were classified as partial, heterozygous, and normal group in our cohort. Again, three partial and one heterozygous variants were detected, while the expected profound for the p.R157H (c.470G>A) homozygous variant was detected. SNPs can also complicate the asymptomatic carrier rate and genotype-phenotype compatibility $(32,34)$. It was reported that some of cases with pathogenic variants were asymptomatic (35) In a previous study, it was reported that the father of a Hungarian child with BTD remained asymptomatic despite having the same variant. The newborn had a partial (enzyme activity $21 \%$ ) phenotype biochemically. The enzyme activity value of the father was not defined in the paper. However, some of the patients who have a partial phenotype biochemically may be asymptomatic, and it is sometimes a matter of discussion whether these patients should be treated or not. One of the explanation for these situations is that low penetrance causes a milder phenotype (30).

Another issue contributing to genotype-phenotype discordance is the uncertainty created by novel variants and patients with BTD without any mutations (36). Clinicians can face the inability to determine whether novel variants are polymorphism or pathogenic states. In some patients with BTD, no mutation may be detected due to molecular analysis limitations, which may cause difficulties in predicting genotypephenotype matching. (37). No mutations were found in the 55 participants in the current cohort. In addition, ten novel variants were identified that were not detected in the databases. Molecular diagnostic difficulties resulting from these patients point to a significant contribution to the total allele pool.

Another important reason for the high frequency of discrepancy is the lack of segregation analysis from parents. Unfortunately, we could not analyze family segregation for all parents, except110 parents in our study. This approach guides the decision of biotin treatment and predicts the clinical course, genetic counseling, and identifying carrier states. It may also be more important due to the genetic heterogeneity caused by autosomal recessive diseases such as BTD, especially in regions where consanguineous marriages are intense, such as the center where the present study was conducted. Therefore, we recommend familial segregation analysis for patients with genotype-phenotype discrepancy.

\section{Conclusion}

The present study reveals that the biotinidase activity increase with age. and there is low genotype-biochemical phenotype concordance in the neonatal period. This indicates the importance of the monitoring the course of biotinidase enzyme activities for a longer period of time to determine the treatment decision. 


\section{Abbreviations}

BT: biotinidase enzyme

BTD:biotinidase deficiency

$\mathrm{C} / \mathrm{H}$ :compound heterozygote

HTZ:heterozygote

HZM:homozygote

M: mild variant

S:severe variant

\section{Declarations}

Funding: No funding

Conflicts of interest/Competing interests: All authors have no conflict of interest

Availability of data and material: The datasets generated during and/or analysed during the current study are available from the corresponding author on reasonable request.

\section{Code availability:N/A}

Author contribution statement: Karaoglan M: Designed, collected data, interpreted analysis and wrote, Nacarkahya G: analyzed genetic data and performed molecular analysis, Aytaç Emel, collected data, Keskin M, designed and collected data

Ethical approval statement: The study was approved by the Gaziantep University Clinical Research Ethics Committee.

Consent to participate: Informed consent was obtained from all individual participants/or their parents included in the study.

\section{Consent for publication:N/A}

\section{References}

1. Zempleni J, Hassan YI, Wijeratne SS. Biotin and biotinidase deficiency. Expert Rev Endocrinol Metab. 2008;3(6):715-724. doi:10.1586/17446651.3.6.715

2. Karaoglan M, Nacarkahya G, Keskin M, Keskin O. Immunophenotypic analysis of lymphocyte subsets in newborns with biotinidase deficiency. Pediatr Allergy Immunol. 2021 Apr;32(3):586-598. doi: 10.1111/pai.13416. Epub 2020 Dec 27. PMID: 33217065.

3. Strovel, E., Cowan, T., Scott, A. et al. Laboratory diagnosis of biotinidase deficiency, 2017 update: a technical standard and guideline of the American College of Medical Genetics and Genomics. Genet Med 19, 1079 (2017).

4. Borsatto T, Sperb-Ludwig F, Lima SE, et al. Biotinidase deficiency: Genotype-biochemical phenotype association in Brazilian patients [published correction appears in PLoS One. 2017 Jun 22;12 (6):e0180463]. PLoS One. 2017;12(5):e0177503.

5. Wiltink RC, Kruijshaar ME, van Minkelen R, Onkenhout W, Verheijen FW, Kemper EA, van Spronsen FJ, van der Ploeg AT, Niezen-Koning KE, Saris JJ, Williams M. Neonatal screening for profound biotinidase deficiency in the Netherlands: consequences and considerations. Eur J Hum Genet. 2016 Oct;24(10):1424-9. doi: 10.1038/ejhg.2016.65. Epub 2016 Jun 22. PMID: 27329734; PMCID: PMC5027693.

6. Neto EC, Schulte J, Rubim R, Lewis E, DeMari J, Castilhos C, Brites A, Giugliani R, Jensen KP, Wolf B. Newborn screening for biotinidase deficiency in Brazil: biochemical and molecular characterizations. Braz J Med Biol Res. 2004 Mar;37(3):295-9. doi: 10.1590/s0100879x2004000300001. Epub 2004 Mar 3. PMID: 15060693

7. Al-Jasmi FA, Al-Shamsi A, Hertecant JL, Al-Hamad SM, Souid AK . Inborn errors of metabolism in the United Arab Emirates: disorders detected by newborn screening (2011-2014). JIMD Rep 2016;28:127-135.

8. Karaca M, Ozgül RK, Unal O, Yucel-Yilmaz D, Kılıc M, et al. Detection of biotinidase gene mutations in Turkish patients ascertained by newborn and family screening. Eur J Pediatr 2015;174:1077-84. 
9. Pomponio RJ, Ozand PT, Al Essa M, Wolf B . Novel mutations in children with profound biotinidase deficiency from Saudi Arabia. J Inherit Metab Dis 2000;23:185-187.

10. Procter M, Wolf B, Crockett DK, Mao R. The Biotinidase Gene Variants Registry: A Paradigm Public Database. G3 (Bethesda). 2013;3:727-31

11. Lara MT, Gurgel-Giannetti J, Aguiar MJ, et al. High Incidence of Biotinidase Deficiency from a Pilot Newborn Screening Study in Minas Gerais, Brazil. JIMD Rep. 2015;24:103-107. doi:10.1007/8904_2015_447

12. László A, Schuler EA, Sallay E, Endreffy E, Somogyi C, Várkonyi A, Havass Z, Jansen KP, Wolf B. Neonatal screening for biotinidase deficiency in Hungary: clinical, biochemical and molecular studies. J Inherit Metab Dis. 2003;26(7):693-8. doi: 10.1023/b:boli.0000005622.89660.59. PMID: 14707518.

13. Al-Eitan LN, Alqa'qa' K, Amayreh W, Khasawneh R, Aljamal H, Al-Abed M, Haddad Y, Rawashdeh T, Jaradat Z, Haddad H. Identification and Characterization of BTD Gene Mutations in Jordanian Children with Biotinidase Deficiency. J Pers Med. 2020 Jan 21;10(1):4. doi: 10.3390/jpm10010004. PMID: 31973013; PMCID: PMC7151559.

14. Cowan TM, Blitzer MG, Wolf B. Technical standards and guidelines for the diagnosis of biotinidase deficiency. Genet Med. 2010;12(7):464-70.

15. Ramaekers VT, Suormala TM, Brab M, Duran R, Heimann G, Baumgartner ER. A biotinidase Km variant causing late onset bilateral optic neuropathy. Arch Dis Child. 1992 Jan;67(1):115-9.

16. Suormala T, Wick H, Baumgartner ER: Low biotinidase activity in plasma of some preterm infants: possible source of false-positive screening results. Eur J Pediatr 1988; 147: 478-480.

17. Vallejo-Torres L, Castilla I, Couce ML, Pérez-Cerdá C, Martín-Hernández E, Pineda M, et al. Cost-Effectiveness Analysis of a National Newborn Screening Program for Biotinidase Deficiency. Pediatrics. 2015 Aug;136(2):e424-32. doi: 10.1542/peds.2014-3399. Epub 2015 Jul 13.

18. Borsatto, T., Sperb-Ludwig, F., Pinto, L.L. et al. Biotinidase deficiency: clinical and genetic studies of 38 Brazilian patients. BMC Med Genet 15, 96 (2014). https://doi.org/10.1186/s12881-014-0096-3

19. Taciane Borsatto, Fernanda Sperb-Ludwig, Samyra E. Lima, Maria R. S. Carvalho, et al. Biotinidase deficiency: Genotype-biochemical phenotype association in Brazilian patients. PLoS One. 2017; 12(5): e0177503. Published online 2017 May 12. doi: 10.1371/journal.pone.0177503

20. Seker Yilmaz B, Mungan NO, Kor D, Bulut D, Seydaoglu G, Öktem M. Twenty-seven mutations with three novel pathologenic variants causing biotinidase deficiency: a report of 203 patients from the southeastern part of Turkey. J Pediatr Endocrinol Metab. 2018 Mar 28;31(3):339-343. doi: 10.1515/jpem-2017-0406

21. Canda E, Yazici H, Er E, Kose M, Basol G, Onay H. Single center experience of biotinidase deficiency: 259 patients and six novel mutations. J Pediatr Endocrinol Metab. 2018 Aug 28;31(8):917-926. doi: 10.1515/jpem-2018-0148.

22. Schulpis KH, Gavrili S, Tjamouranis J, Karikas GA, Kapiki A, Costalos C. The effect of neonatal jaundice on biotinidase activity. Early Hum Dev. 2003 May;72(1):15-24.

23. Swango KL, Demirkol M, Hüner G, Pronicka E, Sykut-Cegielska J, Schulze A,et al. Partial biotinidase deficiency is usually due to the D444H mutation in the biotinidase gene. Hum Genet. 1998 May;102(5):571-5.

24. Norrgard et al. Double mutation [A171T and D444H] is a common cause of profound biotinidase deficiency in children ascertained by newborn screening in the United States. Hum Mutat 1998, 11:410.

25. Mühl A, Möslinger D, Item CB, Stöckler-Ipsiroglu S. Molecular characterisation of 34 patients with biotinidase deficiency ascertained by newborn screening and family investigation. Eur J Hum Genet. 2001 Apr;9(4):237-43.

26. Işeri-Erten SÖ, Dikmen ZG, Ulusu NN. Comparison of Spectrophotometric and Fluorimetric Methods in Evaluation of Biotinidase Deficiency. J Med Biochem. 2016;35(2):123-129. doi:10.1515/jomb-2016-0004

27. Kasapkara ÇS, Akar M, Özbek MN, Tüzün H, Aldudak B, Baran RT, Tanyalçın T. Mutations in BTD gene causing biotinidase deficiency: a regional report. J Pediatr Endocrinol Metab. 2015 Mar;28(3-4):421-4. doi: 10.1515/jpem-2014-0056. PMID: 25423671.

28. Baykal T, Gokcay G, Gokdemir Y, Demir F, Seckin Y, Demirkol M, et al. Asymptomatic adults and older siblings with biotinidase deficiency ascertained by family studies of index cases. J Inherit Metab Dis. 2005;28(6):903-12

29. Pomponio RJ, Hymes J, Reynolds TR, Meyers GA, Fleischhauer K, Buck GA, Wolf B. Mutations in the human biotinidase gene that cause profound biotinidase deficiency in symptomatic children: molecular, biochemical, and clinical analysis. Pediatr Res. 1997 Dec;42(6):840-8. doi: 10.1203/00006450-199712000-00020. PMID: 9396567. 
30. Cassa CA, Tong MY, Jordan DM. Large numbers of genetic variants considered to be pathogenic are common in asymptomatic individuals. Hum Mutat. 2013;34(9):1216-1220. doi:10.1002/humu.22375

31. Ramírez-Bello J, Jiménez-Morales M. Implicaciones funcionales de los polimorfismos de un solo nucleótido (SNP) en genes codificantes de proteínas y no codificantes en enfermedades multifactoriales [Functional implications of single nucleotide polymorphisms (SNPs) in protein-coding and non-coding RNA genes in multifactorial diseases]. Gac Med Mex. 2017 MarApr;153(2):238-250. Spanish. PMID: 28474710

32. Shastry BS. SNPs: impact on gene function and phenotype. Methods Mol Biol. 2009;578:3-22. doi: 10.1007/978-1-60327-411-1_1. PMID: 19768584.

33. Pomponio RJ, Ozand PT, Al Essa M, Wolf B . Novel mutations in children with profound biotinidase deficiency from Saudi Arabia. J Inherit Metab Dis 2000;23:185-187.

34. Esaki, S., Malkaram, S. \& Zempleni, J. Effects of single-nucleotide polymorphisms in the human holocarboxylase synthetase gene on enzyme catalysis. Eur J Hum Genet 20, 428-433 (2012).

35. Milánkovics I, Kámory E, Csókay B, Fodor F, Somogyi C, Schuler A. Mutations causing biotinidase deficiency in children ascertained by newborn screening in Western Hungary. Mol Genet Metab. 2007 Mar;90(3):345-8. doi: 10.1016/j.ymgme.2006.11.005. Epub 2006 Dec 20. PMID: 17185019.

36. Mani A. Pathogenicity of De Novo Rare Variants: Challenges and Opportunities. Circ Cardiovasc Genet. 2017;10(6):e002013. doi:10.1161/CIRCGENETICS.117.002013

37. Procter M, Wolf B, Mao R. Forty-eight novel mutations causing biotinidase deficiency. Mol Genet Metab. 2016 Mar;117(3):369-72.

\section{Tables}

Table 1: Comparison of mean biotinidase activities by sequential four tests in the biochemical phenotype subgroups classified depend on highest enzyme activity over different time periods 


\begin{tabular}{|c|c|c|c|c|c|c|c|c|}
\hline \multirow{2}{*}{$\begin{array}{l}\text { Relevant } \\
\text { clinical } \\
\text { phenotypes }\end{array}$} & \multirow[t]{2}{*}{$\begin{array}{l}\text { Biochemcial } \\
\text { phenotype }\end{array}$} & \multirow{2}{*}{$\begin{array}{l}\text { Patients } \\
\text { performed } \\
\text { sequential } \\
\text { four tests } \\
\text { (n) }\end{array}$} & \multirow{2}{*}{$\begin{array}{l}\text { Mean } \\
\text { enzyme } \\
\text { activity } \\
\text { Mean } \\
\text { testing } \\
\text { age } \\
\pm \text { SD } \\
\text { (days) }\end{array}$} & \multicolumn{5}{|c|}{$\begin{array}{l}\text { Biotinidase enzyme activity measurements (mean ezyme activity, } \\
\pm \text { SD) }\end{array}$} \\
\hline & & & & First test & Second test & Third test & Fourth test & $p$ \\
\hline \multirow{6}{*}{ Treated } & \multirow{3}{*}{$\begin{array}{l}\text { Profound } \\
(n=22) \\
\text { F/M (10/12) }\end{array}$} & & $\begin{array}{l}\text { Age at } \\
\text { testing } \\
\text { time }^{\beta}\end{array}$ & $19.56 \pm 8.22$ & $71.98 \pm 23.63$ & $216.34 \pm 75.34$ & $280.45 \pm 90.56$ & \\
\hline & & $(n=8)$ & $\begin{array}{l}\text { Mean } \\
\text { enzyme } \\
\text { activity }\end{array}$ & $8.68 \pm 2.54$ & $6.67 \pm 3.19$ & $8.16 \pm 2.95$ & $6.16 \pm 2.34$ & 0.525 \\
\hline & & $\mathrm{F} / \mathrm{M}(4 / 4)$ & & & & & & \\
\hline & $\begin{array}{l}\text { Partial } \\
(n=95)\end{array}$ & & $\begin{array}{l}\text { Age at } \\
\text { testing } \\
\text { time }^{\beta}\end{array}$ & $27.33 \pm 14.73$ & $66.43 \pm 42.74$ & $231.34 \pm 80.23$ & $486.21 \pm 182.42$ & \\
\hline & F/M (54/40) & $(n=33)$ & $\begin{array}{l}\text { Mean } \\
\text { enzyme } \\
\text { activity }\end{array}$ & $18.03 \pm 6.21$ & $19.27 \pm 6.48$ & $16.48 \pm 7.40$ & $18.36 \pm 10.21$ & 0.483 \\
\hline & & $\begin{array}{l}\mathrm{F} / \mathrm{M} \\
(23 / 10)\end{array}$ & & & & & & \\
\hline \multirow{9}{*}{ Untreated } & Heterozygous & & $\begin{array}{l}\text { Age at } \\
\text { testing } \\
\text { time }^{\beta}\end{array}$ & $34.79 \pm 14.58$ & $55.31 \pm 22.37$ & $177.63 \pm 95.36$ & $558.72 \pm 218.34$ & \\
\hline & $(n=333)$ & $(n=61)$ & $\begin{array}{l}\text { Mean } \\
\text { enzyme } \\
\text { activity }\end{array}$ & $26.66 \pm 10.61$ & $29.41 \pm 11.96$ & $32.76 \pm 14.10$ & $35.91 \pm 14.98$ & $0.016^{*}$ \\
\hline & $\begin{array}{l}\mathrm{F} / \mathrm{M} \\
(151 / 182)\end{array}$ & $\begin{array}{l}\mathrm{F} / \mathrm{M} \\
(27 / 34)\end{array}$ & & & & & & \\
\hline & Normal & & $\begin{array}{l}\text { Age at } \\
\text { testing } \\
\text { time }^{\beta}\end{array}$ & $37.38 \pm 22.10$ & $49.30 \pm 13.89$ & $154.57 \pm 87.54$ & $387.53 \pm 176.40$ & \\
\hline & $(n=261)$ & $(n=50)$ & $\begin{array}{l}\text { Mean } \\
\text { enzyme } \\
\text { activity }\end{array}$ & $42.59 \pm 31.90$ & $52.09 \pm 31.90$ & $68.18 \pm 41.41$ & $73.04 \pm 34.58$ & $<0.001^{*}$ \\
\hline & $\begin{array}{l}\text { F/M } \\
(110 / 151)\end{array}$ & $\begin{array}{l}\mathrm{F} / \mathrm{M} \\
(21 / 29)\end{array}$ & & & & & & \\
\hline & \multirow{3}{*}{$\begin{array}{l}\text { Heterozgous } \\
\text { plus Normal } \\
(\mathrm{n}=594) \\
\text { F/M } \\
(261 / 333)\end{array}$} & & $\begin{array}{l}\text { Age at } \\
\text { testing } \\
\text { time }^{\beta}\end{array}$ & $30.33 \pm 20.41$ & $54.65 \pm 22.72$ & $211.44 \pm 110.45$ & $542.65 \pm 198.54$ & \\
\hline & & $(n=111)$ & $\begin{array}{l}\text { Mean } \\
\text { enzyme } \\
\text { activity }\end{array}$ & $33.83 \pm 24.07$ & $39.62 \pm 25.69$ & $48.71 \pm 34.97$ & $50.56 \pm 29.46$ & $<0.001^{*}$ \\
\hline & & $\begin{array}{l}\mathrm{F} / \mathrm{M} \\
(49 / 62)\end{array}$ & & & & & & \\
\hline
\end{tabular}

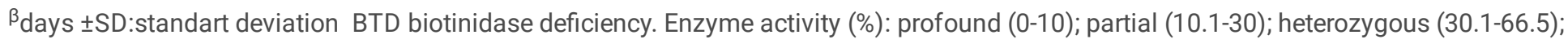
normal (>66.6) Enzyme activity is given percent (\%) of mean reference ranges of healthy children. One-way repeated measure ANOVA test was used in children performed four sequential test over different time periods. Biochemical phenotypes were classified depend on highest enzyme activity over different time periods after four sequential tests.

${ }^{*} \mathrm{p}$ value is signifiant at $<0.05$ 
Table 2:The distribution of the most common alleles between the biochemical phenotype groups based on highest enzyme activity over different time periods and mean enzyme activity values for the first test in neonatal period and the highest test over different time point in each group

\begin{tabular}{|c|c|c|c|c|c|c|c|c|c|c|c|c|c|c|}
\hline \multirow[t]{2}{*}{ Genotype } & \multicolumn{2}{|c|}{ Allele total } & \multirow[t]{2}{*}{ Zigosity } & \multicolumn{2}{|c|}{ Alleles } & \multirow[b]{2}{*}{$\begin{array}{l}\text { The number } \\
\text { of tests }^{\beta}\end{array}$} & \multicolumn{2}{|c|}{$\begin{array}{l}\text { First test value in neonatal } \\
\text { period }\end{array}$} & \multicolumn{2}{|c|}{$\begin{array}{l}\text { Highest test value over } \\
\text { different time points }\end{array}$} & \multicolumn{4}{|c|}{ Biochemical phenotype groups* } \\
\hline & $\mathrm{N}$ & $\%$ & & $\mathrm{~N}$ & $\%$ & & Mean & Min-Max & Mean & Min-max & Profound & Partial & Heterozygous & Normal \\
\hline \multirow{3}{*}{$\begin{array}{c}\text { p.D444H } \\
\text { (c. } 1330 \mathrm{G}>\mathrm{C})\end{array}$} & \multirow{3}{*}{385} & \multirow{3}{*}{47.47} & HMZ & 141 & 17,07 & 337 & $38.68 \pm 19.06$ & $3.0-140$ & $55.88 \pm 24.70$ & $3.9-170$ & 3 & 8 & 100 & 30 \\
\hline & & & HTZ & 112 & 13,56 & 239 & $58.85 \pm 31.02$ & $2.1-170$ & $81.93 \pm 32.89$ & $17.1-180$ & 0 & 3 & 39 & 70 \\
\hline & & & $\mathrm{C} / \mathrm{H}$ & 132 & 15,98 & 375 & $31.77 \pm 20.64$ & $3.6-140$ & $45.88 \pm 26.17$ & $4.9-115.3$ & 1 & 33 & 78 & 20 \\
\hline \multirow{2}{*}{$\begin{array}{c}\text { p.R157H } \\
(\mathrm{c} .470 \mathrm{G}>\mathrm{A})\end{array}$} & \multirow[b]{2}{*}{149} & \multirow[b]{2}{*}{18.3} & HMZ & 23 & 2,78 & 71 & $15.61 \pm 7.81$ & $2.9-38$ & $22.11 \pm 13.39$ & $3-73$ & 3 & 17 & 2 & 1 \\
\hline & & & HTZ & 65 & 7,87 & 140 & $43.93 \pm 21.88$ & $9-120$ & $69.98 \pm 30.34$ & $15-220$ & 0 & 3 & 30 & 32 \\
\hline p.C 33 Ffs & \multirow{3}{*}{73} & \multirow{3}{*}{9.00} & $\mathrm{HMZ}$ & 10 & 1,21 & 37 & $8.46 \pm 3.47$ & $1.2-12$ & $18.11 \pm 13.76$ & $6.9-53$ & 6 & 3 & 1 & 0 \\
\hline \multirow{2}{*}{$\begin{array}{c}\text { (c.198_104delGCGGC } \\
\text { TGinsTCC) }\end{array}$} & & & HTZ & 35 & 4,24 & 128 & $40.50 \pm 16.69$ & $6-72$ & $65.31 \pm 25.75$ & $17-150$ & 0 & 1 & 22 & 12 \\
\hline & & & $\mathrm{C} / \mathrm{H}$ & 28 & 3,39 & 108 & $22.21 \pm 11.82$ & $4.1-44$ & $34.94 \pm 11.43$ & $9.7-65$ & 2 & 14 & 12 & 0 \\
\hline \multirow{3}{*}{$\underset{(c .1595 \mathrm{C}>\mathrm{T})}{\text { p.T532M }}$} & \multirow{3}{*}{47} & \multirow{3}{*}{5.79} & $\mathrm{HMZ}$ & 0 & 0,00 & no & no & no & no & no & no & no & no & no \\
\hline & & & HTZ & 25 & 3,03 & 64 & $43.72 \pm$ & $4.7-130$ & $66.99 \pm$ & $34.1-130$ & 0 & 0 & 16 & 9 \\
\hline & & & $\mathrm{C} / \mathrm{H}$ & 22 & 4,48 & 60 & $21.88 \pm 13.74$ & $1.1-53$ & $41.00 \pm 28.94$ & $12.2-130$ & 2 & 10 & 5 & 5 \\
\hline \multirow{3}{*}{$\begin{array}{l}\text { p. Q456H } \\
(\text { c. } 1368 \mathrm{~A}>\mathrm{C})\end{array}$} & \multirow{3}{*}{42} & \multirow{3}{*}{5.17} & $\mathrm{HMZ}$ & 9 & 1,09 & 28 & $11.72 \pm 7.18$ & $1.7-20.4$ & $19.11 \pm 5.87$ & $9.2-33$ & 3 & 5 & 1 & 0 \\
\hline & & & HTZ & 25 & 3,03 & 65 & $42.63 \pm 27.80$ & $1.1-130$ & $70.34 \pm 32.59$ & $8.6-103$ & 1 & 2 & 9 & 13 \\
\hline & & & $\mathrm{C} / \mathrm{H}$ & 8 & 0,97 & 28 & $29.45 \pm 5.23$ & $12-51$ & $42.65 \pm 5.14$ & $18-102.6$ & 0 & 3 & 4 & 1 \\
\hline$($ c. $968 \mathrm{~A}>\mathrm{G})$ & & & HTZ & 7 & 0,85 & 9 & $55.41 \pm 31.43$ & $3.6-109.5$ & $70.10 \pm 25.15$ & $42-109.5$ & 0 & 0 & 5 & 2 \\
\hline & & & $\mathrm{C} / \mathrm{H}$ & 7 & 0,85 & 16 & $44.84 \pm 21.81$ & $20-73$ & $55.12 \pm 20.90$ & $26.9-78.9$ & 0 & 2 & 2 & 3 \\
\hline p.R79C & & & $\mathrm{HMZ}$ & 2 & 0,24 & 7 & $24.5 \pm 20.50$ & $10-39$ & $32 \pm 9.89$ & $25-39$ & 0 & 1 & 1 & 0 \\
\hline$(c .235 \mathrm{C}>\mathrm{T})$ & 20 & 2,46 & HTZ & 9 & 1,09 & 22 & $43.72 \pm 22.81$ & $9.9-70$ & $41.32 \pm 20.67$ & $35-114$ & 0 & 0 & 3 & 6 \\
\hline & & & $\mathrm{C} / \mathrm{H}$ & 9 & 1,09 & 30 & $48.33 \pm 35.83$ & $24-140$ & $69.30 \pm 45.69$ & $28.9-140$ & 0 & 1 & 5 & 3 \\
\hline p.R209C & & & $\mathrm{HMZ}$ & 1 & 0,12 & 4 & 22 & $22-22$ & $22-22$ & $22-22$ & 0 & 1 & 0 & 0 \\
\hline$(c .625 \mathrm{C}>\mathrm{T})$ & 9 & 1,10 & HTZ & 3 & 0,36 & 7 & $62.1 \pm 13.13$ & $48-74$ & $116.76 \pm 72.8$ & $64.3-200$ & 0 & 0 & 1 & 2 \\
\hline & & & $\mathrm{C} / \mathrm{H}$ & 5 & 0,61 & 16 & $30.94 \pm 13.71$ & $16.7-47$ & $50.9 \pm 13.61$ & $39.5-73$ & 0 & 0 & 4 & 1 \\
\hline p.N202I & & & $\mathrm{HMZ}$ & 3 & 0,36 & 8 & $12.66 \pm 0,57$ & $12-13$ & $16 \pm 5,19$ & $13-22$ & 0 & 3 & 0 & 0 \\
\hline$(c .605 \mathrm{~A}>\mathrm{T})$ & 9 & 1,10 & HTZ & 2 & 0,24 & 5 & $21 \pm 11.31$ & $13-26$ & $27.5 \pm 2.12$ & $26-29$ & 0 & 2 & 0 & 0 \\
\hline & & & $\mathrm{C} / \mathrm{H}$ & 4 & 0,48 & 10 & $19.6 \pm 13.46$ & $6.4-34$ & $40.5 \pm 19.82$ & $28-70$ & 0 & 1 & 2 & 1 \\
\hline p.L69Hfs $=24$ & & & $\mathrm{HMZ}$ & 0 & 0,00 & no & - & - & - & - & - & - & - & \\
\hline (c.192_193insCATC) & 6 & 0,73 & HTZ & 3 & 0,36 & 9 & $63.66 \pm 31.08$ & $28-85$ & $88.33 \pm 10.69$ & $78-99$ & 0 & 0 & 0 & 3 \\
\hline & & & $\mathrm{C} / \mathrm{H}$ & 3 & 0,36 & 5 & $36.96 \pm 31.20$ & $6-68.4$ & $47.63 \pm 18.0$ & $36.5-68.4$ & 0 & 0 & 2 & 1 \\
\hline p.Cysl86Tyr & & & $\mathrm{HMZ}$ & 0 & 0,00 & no & - & - & - & - & - & - & - & - \\
\hline$($ c.557G $>\mathrm{A})$ & 7 & 0,86 & HTZ & 4 & 0,36 & 12 & $44.5 \pm 21.12$ & $27-75$ & $68.25 \pm 15.79$ & $41-75$ & 0 & 0 & 2 & 1 \\
\hline & & & $\mathrm{C} / \mathrm{H}$ & 3 & 0,36 & 8 & $28.63 \pm 20.60$ & $4.9-42$ & $31.8 \pm 15.14$ & $14.4-42$ & 0 & 1 & 2 & 0 \\
\hline OTHER & 49 & 6,04 & $\mathrm{HMZ}$ & 3 & 0,12 & 10 & $52.10 \pm 43.58$ & $22-102$ & $75.33 \pm 37.85$ & $32-102$ & 0 & 0 & 1 & 2 \\
\hline
\end{tabular}

HMZ:homozygote HTZ: heterozygote C/H: compound heterozygote no: not detectable. Enzyme activities (\%): profound (0-10), partial (10.1-30), heterozygous (30.1-66.5), normal (>66.6). *Biochemical phenotypes were classified based on highest enzyme activity over different tme points after four sequential tests. due to p.H323R, (c.968A>G) variant is only one variant mean value was not calculated. ${ }^{B}$ The number of tests: Total number of biotindase enzyme activity measurements performed over different time points

Table 3: The concordance between genotype and biochemical phenotype 


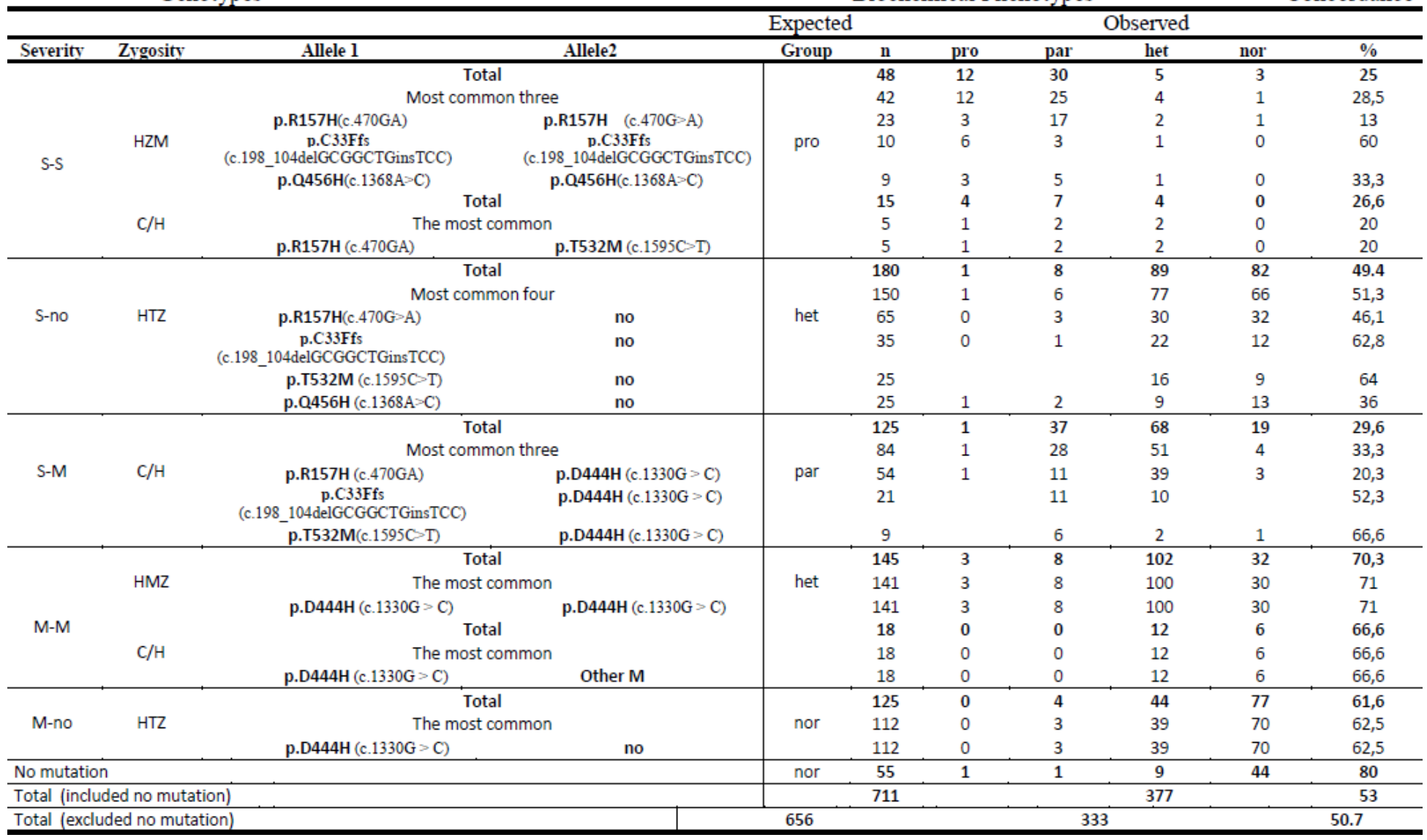

* Biochemical phenotypes were classified based on highest enzyme activity over different tme points after four sequential tests no: not detactable. Biochemical phenotypes based on enzyme activity (\%): profound (0-10); partial (10.1-30); heterozygous (30.1-66.5); normal (>66.6) Enzyme activity is given percent (\%) of mean reference ranges of healthy children. When the heterozygous group was added to the normal group, concordance rates were as follows: $95 \%, 91 \%, 96.8 \%$, and $96.3 \%$ for S-no, $M-M, M-n o$, and no mutation genotype groups.

Figures 


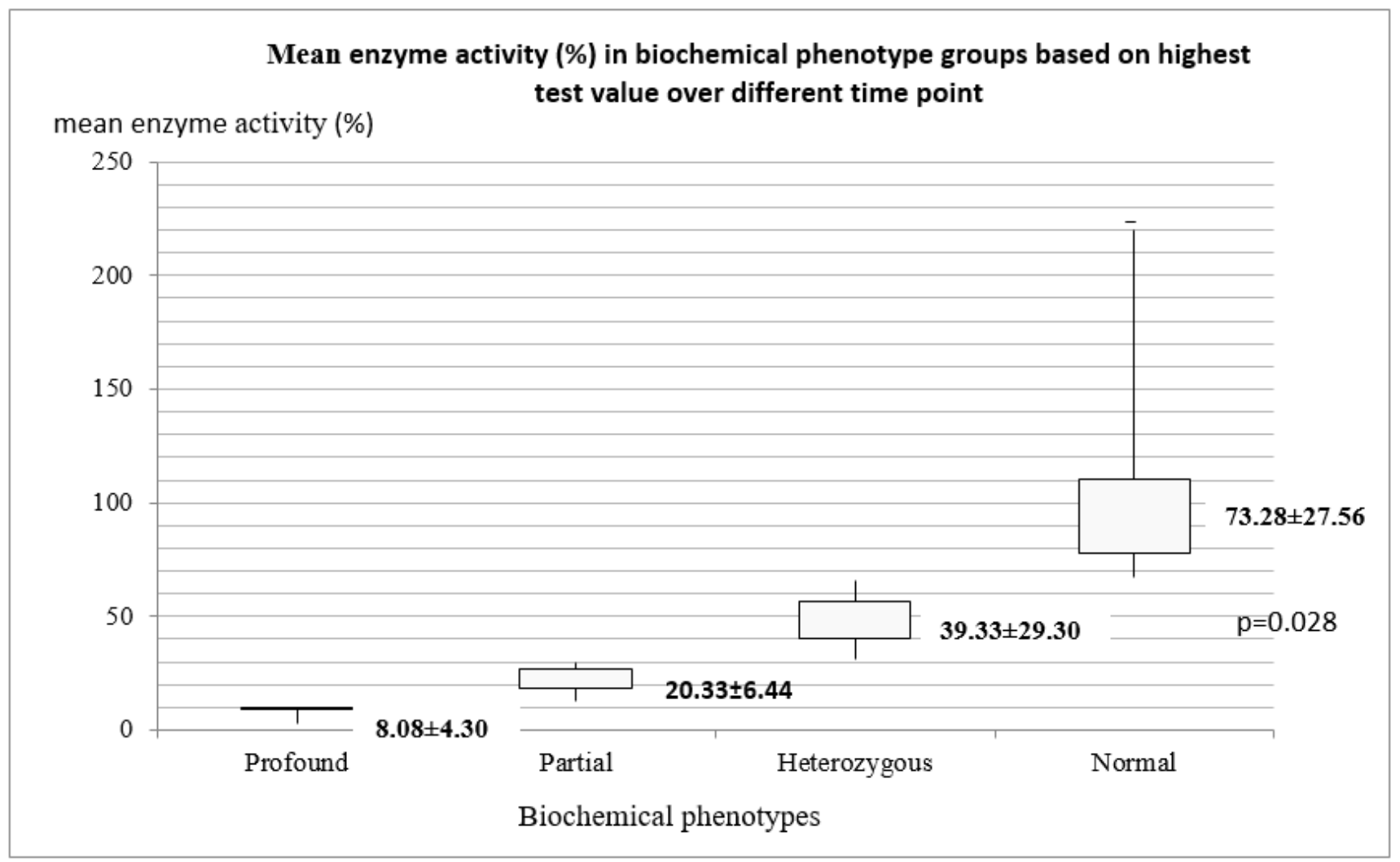

Figure 1

The mean biotinidase enzyme activities between biochemical phenotype groups based on highest test values over different time points after four sequential tests. Biochemical pheotypes were classfied based on the highest enzyme activity over different time points after four sequential test. Minumum and maximum enzyme activity values (\%) for each biochemical phenotype: Profund (min-max 3-9.9 ); Partial (min-max 13-30); Heterozygous (min-max 31-66); Normal (min-max 67-220) One way ANOVA test used. p is significant <0.05

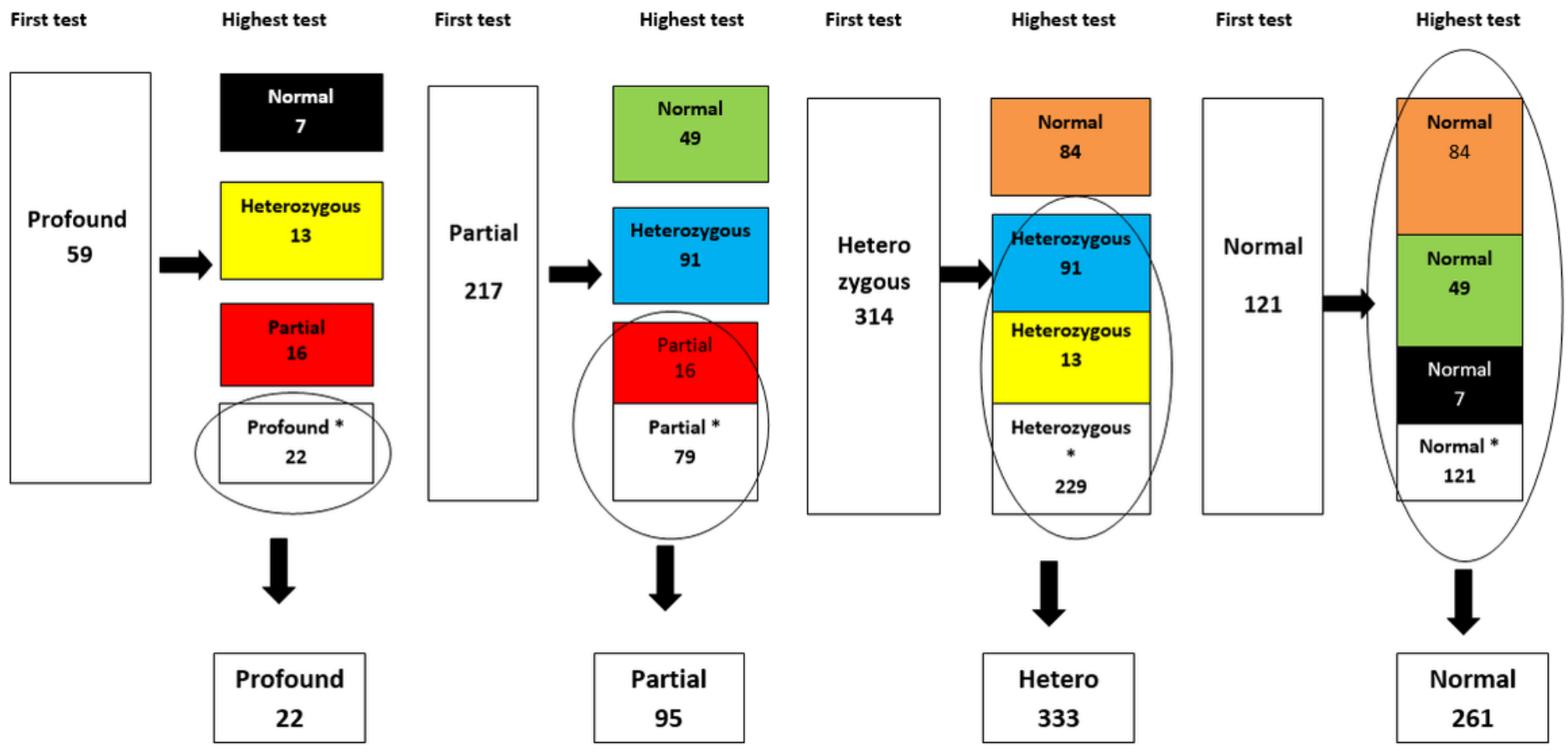

Figure 2 
Changes in the number of participants in the biochemical phenotype groups based on the first enzyme activity in the neonatal period and the highest enzyme activity over different time points after four sequential tests * The number of participants whose biochemical group did not change based-on first test during the neonatal period and the highest test performed over different time points. Biochemical phenotypes based on enzyme activity (\%): profound (0-10); partial (10.1-30); heterozygous (30.1-66.5); normal (>66.6) Enzyme activity is given percent (\%) of mean reference ranges of healthy children.

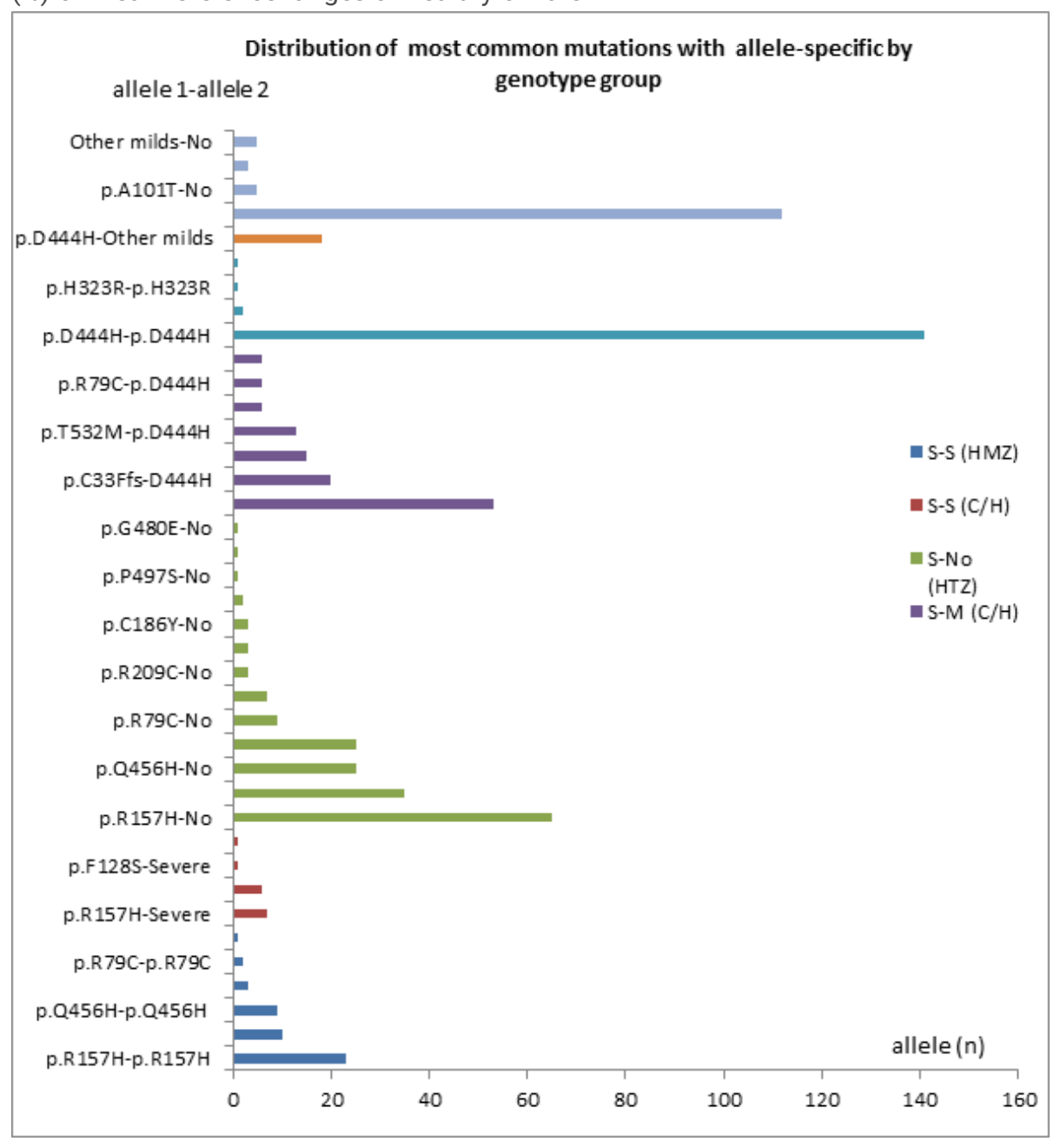

\section{Figure 3}

The distribution of most common mutations with allele-specific by genotype group S:severe M:mild HMZ: homozygote HTZ: heterozygote $\mathrm{C} / \mathrm{H}$ : compound heterozygote 


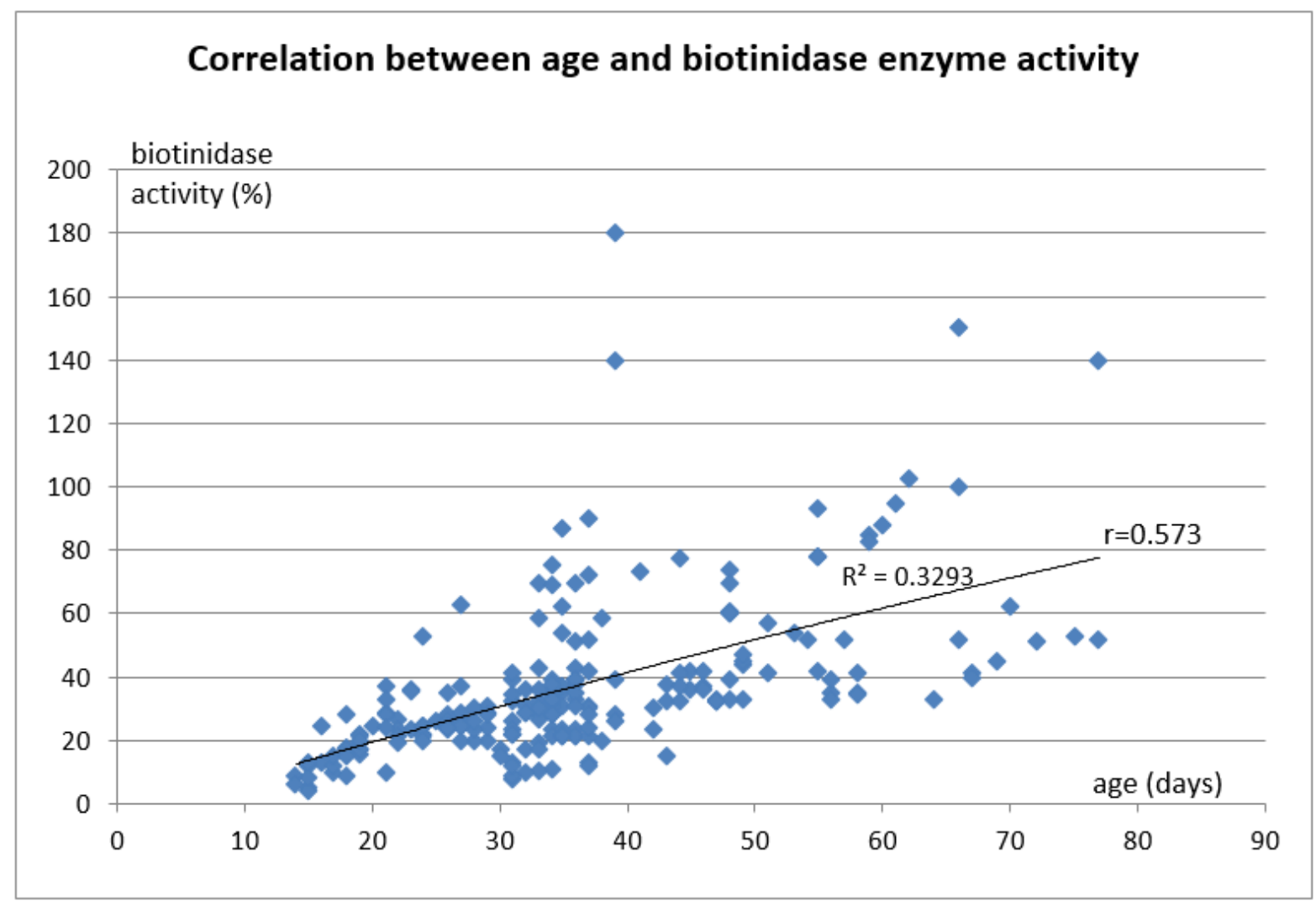

Figure 4

Correlation between biotinidase enzyme activity (\%) and age (days) in heterozygous plus normal biochemical phenotype groups in first months Pearson correlation test was used in untreated group $(n=111)$ (heterozygous $(n=61)$ plus normal $(n=50)$ biochemcial phenotype). Participants consist of dignosed with heterozygous and normal biochemical phenotypes based on the highest test after four sequential test over different time points 